\title{
Chasing the Double-Bottom Line: Fair Trade and the Elusive Win-Win
}

Curtis Child

Brigham Young University - Provo, cchild@byu.edu

Follow this and additional works at: https://scholarsarchive.byu.edu/facpub

Part of the Work, Economy and Organizations Commons

\section{BYU ScholarsArchive Citation}

Child, Curtis, "Chasing the Double-Bottom Line: Fair Trade and the Elusive Win-Win" (2012). Faculty Publications. 3881.

https://scholarsarchive.byu.edu/facpub/3881

This Book Chapter is brought to you for free and open access by BYU ScholarsArchive. It has been accepted for inclusion in Faculty Publications by an authorized administrator of BYU ScholarsArchive. For more information, please contact ellen_amatangelo@byu.edu. 


\title{
Chasing the Double-Bottom Line: Fair Trade and the Elusive Win-Win
}

\author{
Curtis Child
}

Social enterprises embody a problematic proposition. They are premised on the idea that it is possible to create simultaneously social and economic value in a direct, explicit way, yet it would seem that each of these goals is in some amount in consequential tension with the other. The argument of social enterprise is nevertheless that one outcome - financial or social returns - need not be seen as the eventual by-product of focusing on the other, but rather that both can be productively pursued in an immediate sense. Scholars have only started to examine in detail how social enterprises accomplish this delicate balancing act.

The literature on social enterprise and social purpose businesses has been primarily concerned with describing the trend broadly (Cooney and Shanks, 2010), contemplating its legal ramifications (Taylor, 2010), advocating for its expansion (Prahalad, 2004; Yunus, 2008; Yunus and Weber, 2010) and providing inspiring accounts as well as how-to or best-practice instructions for aspiring social entrepreneurs (Bornstein, 2004; Lynch and Walls, 2009). Some work has been more critical (e.g. Edwards, 2008). But, with few exceptions (such as Cooney, 2006), the literature has failed to problematize adequately social enterprise, thus overlooking its sometimes contradictory nature while broadcasting its perceived benefits.

If we approach social enterprise with a critical eye - as something that must be accomplished rather than something that just is - then certain questions immediately become evident. The one I reflect on in this chapter is: How do social enterprises balance their dual commitments to prosocial and financial goals? We cannot answer this question until we first understand the ambiguous institutional terrain on which social enterprises operate, so I propose a schema for thinking about the matrix of options available to social enterprises as well as their variable consequences. I then discuss how well commonsense expectations derived from the schema reflect reality, using the fair trade industry as a reference point. Doing so highlights some unexpected results. For example, it turns out that being able to act in ways that increase the likelihood of maximizing social and financial 
returns - the Holy Grail of social enterprise - is actually more challenging than it might seen from a distance, and fair trade businesses will often be required to forego one goal while in pursuit of the other. Although most observers would not be surprised to learn that businesses will favor financial commitments over social ones, it is perhaps more difficult to understand the circumstances under which such ventures would pursue prosocial ends if they interfered with revenue potential - especially considering the market pressures under which for-profit enterprises operate. I use the case of Coastal Coffees to illustrate not only the inherent complexity of social enterprise generally but in order to provide one explanation for why, if market pressures exert such a compelling force on for-profit social enterprises, these organizations might be willing to hold them in check. Data collected during a three-year investigation of two social enterprise industries - fair trade and socially responsible investing - suggest that there is not a simple answer to why businesses would pursue social goals even if a financial calculus would compel them to do otherwise. There are a variety of mechanisms that serve to keep organizations focused on their social missions, and I focus on one that is evident in the fair trade industry - namely, the effect that first-hand encounters with the communities impacted by their business decisions can have on social business practitioners.

\section{Background and data}

The empirical context for this chapter is the fair trade industry. According to FINE (Krier, 2008, 23), an international network of fair trade organizations, "fair trade" is

a trading partnership, based on dialogue, transparency and respect, that seeks greater equity in international trade. It contributes to sustainable development by offering better trading conditions to, and securing the rights of, marginalized producers and workers - especially in the South. Fair Trade organizations (backed by consumers) are actively engaged in supporting producers, in awareness raising and in campaigning for changes in the rules and practices of conventional international trade.

Fair trade businesses, therefore, are social enterprises par excellence. As forprofit ventures, they are committed to financial returns, yet as participants to the fair trade movement, they also have decidedly prosocial ambitions. They operate in the for-profit marketplace, but they do so in unconventional ways by actively pursuing social goals alongside monetary ones. For this reason, they are ideal sites to examine the complexities of this particular organizational form.

As a movement, the history of fair trade reaches back to at least the 1940s and 1950s, when European groups such as Oxfam UK and Fair Trade Original 
(a Dutch organization) began importing and retailing goods produced by artisans from the global South with the explicit goal of supporting economic and community development (see Fridell, 2007). In the 1950s and 1960s, US groups such as the Mennonite's Central Committee and the Church of the Brethren likewise began supporting the fair trade cause (eventually evolving into Ten Thousand Villages and SERRV, respectively). Other organizations, such as Equal Exchange in the early 1980s, followed suit.

The fair trade movement grew considerably over the next 30 years. By 2008, Fair Trade USA (formerly TransFair USA), a US-based fair trade certification initiative, boasted that it was responsible for tracking the supply chains between more than 800 US companies and the 1.5 million farmers from whom they source, auditing in the process more than 40,000 interactions between producers, importers and manufacturers (TransFair USA, 2010). In 2010, Fair Trade USA imported nearly 110 million pounds of fair trade certified coffee, along with 51 million pounds of produce, 18 million pounds of sugar, 4 million pounds of cocoa and nearly 10 million flower stems, as well as millions of pounds of tea, grain, spice, honey and wine (Fair Trade USA, 2010). Total retail sales for the year were $\$ 1.2$ billion (TransFair USA, 2010). As much as they demonstrate the tremendous growth of the movement, these figures actually underestimate the scope of the fair trade market, since they do not include the sales of goods for which no certification exists, such as handicrafts and textiles. Nor do they represent fair trade transactions that are monitored by other certification initiatives, such as the Fair for Life Social \& FairTrade Certification Programme (a certification initiative that has recently been growing in popularity), Utz Certified, the Rainforest Alliance, and others.

As part of a larger study, I conducted 40 semi-structured interviews with members of 30 fair trade businesses between 2009 and 2011, supplemented with participation and observations (including numerous informal interviews) at industry conferences and other events. Because of space limitations, I have drawn selectively on these data (but see Child, 2011 for more detail).

\section{Conceptualizing social enterprise outcomes}

Conceptually, we can think of social enterprises as pursuing two goals: social returns and financial returns (see Figure 8.1). From this perspective, practitioners make decisions that can have four ideal-typical outcomes the most desired one being the so-called win-win outcome that increases the likelihood of maximizing both prosocial and economic returns. When faced with such a possibility, the obvious choice is to pursue it. A second possibility is that a decision leads the company to diminish the likelihood of maximizing social and economic returns. In this case, the organization would unproblematically avoid the situation. A third (and fourth) scenario 


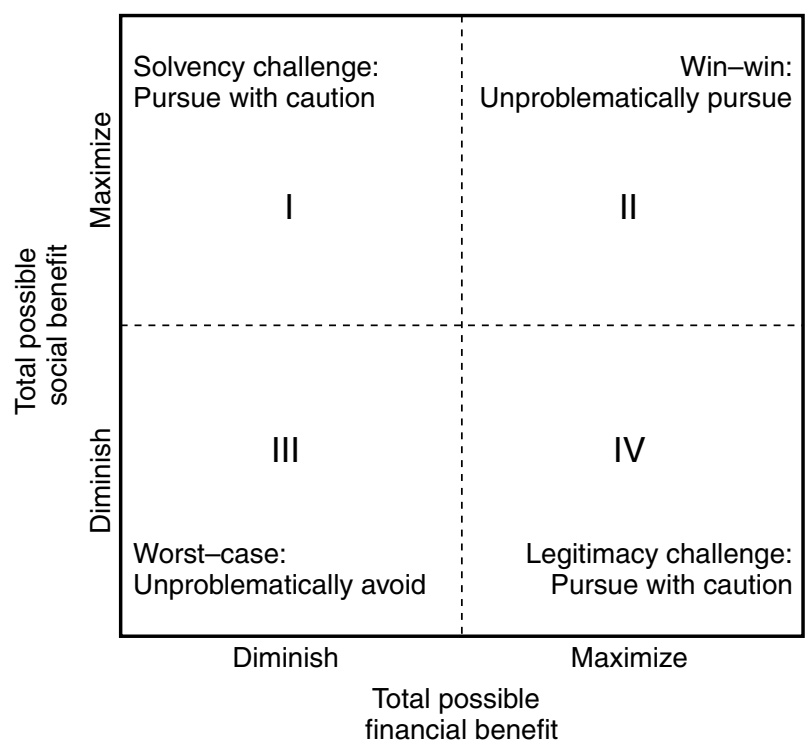

Figure 8.1 Ideal-typical outcomes for social enterprise decisions

is that one goal must be tempered in favor of the other. On the one hand, a decision could increase the likelihood of maximizing social benefit while decreasing the likelihood of maximizing financial returns. Or, a decision could increase the prospects of maximizing financial benefit but diminish the chances of maximizing social returns.

Decisions that locate an organization within quadrants I or IV have particularly interesting implications. First, a social enterprise that consistently favors its social goals over its financial ones risks insolvency. Although the likelihood of achieving the prosocial mission increases, its financial prospects diminish. This is especially an issue for for-profit ventures, which are subject to the full force of market dynamics that cannot typically be cushioned through the receipt of philanthropic support in the same way that nonprofits can. Consistently favoring financial goals at the expense of social ones makes it more likely that the enterprise will remain solvent, but it does present the organization with a potential legitimacy problem. If relevant stakeholders perceive the venture as focused more on earning revenues than providing a social benefit, then their support for it will likely wane and its credibility will suffer.

Based on a logical reading of Figure 8.1, what empirical patterns might we expect to find among actual social enterprise ventures? Two choices are clear: avoid quadrant III and pursue quadrant II. One might assume that businesses would never (or at least rarely) pursue social mission over 
economic concerns (quadrant I) because the risks to the business's financial health - what I have labeled the solvency challenge - would be too great. Social enterprises might, however, make decisions that locate them in quadrant IV if they can devise ways to deal with the attendant legitimacy challenge, which they can do by taking advantage of the abundant rhetorical resources that are available to them. Spurred by the corporate social responsibility movement, a constellation of justifications and tropes have been used to frame virtually any business-oriented activity as prosocial. In the language of Figure 8.1, discursive resources are available to organizations that, if used, can help them to deal with credibility problems (quadrant IV) by framing decisions and their outcomes as actually consistent with quadrant II. That is, even decisions that clearly favor economic benefit over social mission can be framed and marketed as "win-win".

How well does reality match these expectations? My research on for-profit social enterprises suggests that this commonsense reading of the optimal decision-choices for social entrepreneurs does not entirely capture what is happening in the fair trade industry. One of the most obvious ways that expectations derived from Figure 8.1 fail to match reality has to do with quadrant II. Although social enterprises aspire to accomplish two goals, in practice market pressures and prosocial ones pull organizations in different directions. Despite the "doing well by doing good" rhetoric that often accompanies such initiatives, social enterprises must frequently make compromises. An importer of fair trade goods, for example, could be personally committed to the ideals of the fair trade mission but may actually find it easier to work with well-established exporting cooperatives rather than other communities that would likely benefit more from the exchange relationship. From a distance, working with any fair trade cooperative would seem to provide evidence of successfully pursuing a social mission, but when one examines the situation more closely it becomes clear that a degree of the prosocial goal has been sacrificed in favor of financial considerations. Although there may be a net social and financial benefit, this does not obviate the fact that the pursuit of one objective can limit the degree to which the other could be obtained. Hidden tradeoffs like these are common among the social enterprise ventures I studied.

Of course, as suggested above, practitioners will often represent their efforts as consistent with the likelihood of maximizing social and financial goals, and for this reason it is important to understand quadrant II. Making decisions that locate the organization within the quadrant means that it can stay financially profitable and at least outwardly committed to the business's social mission.

Insofar as quadrant I is concerned, there is some evidence to support the idea that social entrepreneurs avoid making decisions that favor social mission over financial security. Practitioners I interviewed spoke with clarity about the necessity of paying attention to market forces. And although they 
often seemed genuinely committed to their business's" prosocial goals, they were not starry-eyed about the realities of operating in the for-profit world. As one fair trader put it, "the market does a real good job of enforcing discipline that we're on our toes on the business side". Even so, practitioners did not altogether shy away from decisions that advanced a social goal while forfeiting the possibility of increased financial returns. In fact, they clearly pursued prosocial goals at times when there were no clear financial incentives for doing so. This is a remarkable observation, which I return to below, since it contradicts behavior that we might otherwise expect from for-profit ventures.

Thus, even though social entrepreneurs promote their efforts as win-win by suggesting that they can increase the likelihood of maximizing financial returns while at the same time maximizing their benefit to society, I have suggested that true win-win scenarios are difficult to come by. Forced from quadrant II, market forces should push organizations into regularly making decisions consistent with quadrant IV. Yet interestingly, data suggest that while some do so, some also make decisions that defy a market rationality by favoring social mission over financial benefit. In the following section, I use the case of Coastal Coffees to illustrate the complicated nature of supposed win-win scenarios and to shed empirical light on how for-profit social enterprise ventures keep their financial ambitions in check in light of the pressures they are under. Doing so ultimately provides insight into how social enterprises balance their dual commitments.

\section{The case of Coastal Coffees}

Coastal Coffees is a family-run, independent business that was established in the 1970s. (The name of the company, the names of the people involved and other identifying information has been changed in accordance with a commitment to anonymity.) Employing roughly 60 people, it imports and roasts green coffee beans from around the world, which it sells under the Coastal Coffees brand as well as a private label. It also operates multiple coffee shops or bars in a mid-sized, progressive, East Coast city. Oliver and Sophie Harper founded the business, but it is now run primarily by their daughter, Kristen.

Although a specialty coffee business, Coastal Coffees did not initially carry fair trade offerings - and had not even interacted much with farmers - until the mid-1990s, when the Harper family went on a coffeebuying trip to Central America. At that point, there was not a robust market for fair trade coffee, and Fair Trade USA (formerly TransFair USA) now a significant certifier and promoter of fair trade coffee - was no more than a few employees in basement cubicles. Kristen was young at the time of the trip, but her parents had spent decades in the coffee industry. Even so, this was, in her words, "one of the first experiences they had 
really witnessing coffee production firsthand", and the result was "very eye opening".

For reasons explained in greater detail below, Coastal Coffees started purchasing fair trade coffee shortly after the aforementioned coffee-buying trip. Signing on with the nascent fair trade movement, Kristen explained, "was a natural conclusion" in light of her family's recent experience. They had seen impoverished farmers in need of willing buyers, and they thought that the East Coast community in which they primarily operated would be excited about the idea of fair trade coffee. Adopting the mantra of social enterprise, Kristen said of the decision to start purchasing fair trade coffee: "it was a win-win. We're small roasters, we get to do more for the farmers, and we get to market ourselves as being socially conscious as opposed to the Big Green Giant across the street."

Based on Kristen's account, at one level it is clear that supporting fair trade was unproblematic for the company. Coastal Coffees could "do well by doing good", and the way forward was clear. In reality, however, the story was more complicated. Although it brands itself as committed to fair trade ideals and employees boast of their pioneering role in the fair trade movement, Coastal Coffees was - and remains - unwilling to let go of conventional (i.e. non-fair-trade) lines of coffee and thus fails to embrace fully the movement's ideals. (Many other fair trade coffee companies, by way of contrast, have chosen to source, roast and/or sell only fairly traded beans. Being a "one hundred percenter" has, in turn, become something of an authenticity test to enthusiasts and supporters.)

When I asked what keeps her company from being completely committed to fair trade, Kristen was quick to mention financial constraints:

What prevents us from going 100 percent fair trade is, more than anything, price sensitivity with some of our major customers. Now that fair trade has gone mainstream, they are interested in carrying one or two fair trade coffees, but they will never be interested in carrying 100 percent fair trade. They feel that consumer demand has reached - I don't want to say that it's not still growing - but there's an equilibrium now ... If you offer at least one fair trade coffee (Starbucks has one fair trade coffee; Walmart has fair trade coffee now), then that's sort of good enough. So, because we have customers who buy a large volume of our coffee as far as our volume is concerned, if we just converted to 100 percent fair trade, then we would either have to take a huge hit on margin or they would probably not want to carry our coffee.

In terms of Figure 8.1, the decision to forego an opportunity to increase its commitment to fair trade in order to ensure better financial returns would locate Coastal Coffees in quadrant IV. Fair trade was, after all, "a really valuable marketing tool for us," Kristen explained, and the business was 
unwilling to pursue further potential prosocial returns if that meant undermining its financial prospects. Using the discursive tools available - the "win-win" language and fair trade friendly marketing - to represent itself as unproblematically increasing the likelihood of maximizing both social and financial goals, Coastal Coffees sought, apparently quite successfully, to avoid the legitimacy challenge that might ensue.

Up to this point, the reading of Coastal Coffees has been consistent with an economics-centered view of social enterprise. It is an account of an organization being fundamentally driven by market dynamics that nevertheless has the public relations savvy to frame its actions as prosocial. Yet there is still more to the story. Despite her candid concession that Coastal Coffee's involvement in fair trade could be a useful marketing tool, Kristen insisted that the impetus for purchasing fair trade coffee was less about financial gain and more about moral commitment:

Fair Trade was the right thing to do so we did it. And the goal was to grow it and make it more part of our company and, you know, I think that it was also potentially a marketing strategy for us. But that was so far down on the list of reasons to do it that it really isn't measurable in terms of how well did it deliver on that potential. 'Cause we were more like, "this is the right thing to do, and we've got to be leaders in this". It was a moral commitment, not a business strategy.

Financial benefit, according to Kristen, was decidedly not the prime motivator:

Our primary reason as a company for doing anything involving fair trade was ethical. I mean, I said it became a marketing tool for us, and there was this idea that "hey, we're going to differentiate ourselves around our commitment to social responsibility". But there was no imperative in the industry to get involved in Fair Trade. We were one of the first people to get involved.

Statements such as these hint at extra-financial motivations and become more believable once it is clear that, for a number of reasons, opening up their offerings to include fair trade coffee was not clearly advantageous to Coastal Coffees from a business standpoint. First, because the movement was not well-established at the time, there was not a ready-made market for fair trade coffee, nor was there a clear way to capitalize on its fair trade involvement. In Kristen's words, "we were going out on a limb". There were few models to follow of how to turn fair trade into a compelling marketing strategy, which was particularly a challenge considering that fair trade coffee, especially in its early years, was criticized for lacking the flavor profile that other specialty coffees could provide. Things 
improved considerably in the ensuing years, but fair trade coffee was not initially known for its quality, which could make for a tough sell. Second, the local community was initially skeptical of Coastal Coffee's claims that money from fair trade coffee sales would actually make it back to farming communities. Even if it did accept fair trade in terms of its humanitarian aims, the progressive community that was the main consumer base for Coastal Coffees was concerned with the viability of the model. Because TransFair, the certification initiative, was still so new, it was not instantly credible. Third, as fair trade did become more common and better recognized, whatever marketing edge it may have initially provided was eroded. Moreover, Coastal Coffees became an active participant in the budding fair trade movement and, defying market incentives, advised other businesses on best-practices for marketing and selling fair trade coffees. For these reasons, moving in the direction of fair trade did not clearly promise financial benefit.

If dealing in fair trade coffees introduced risk and had, at times, ambiguous benefits, why did Coastal Coffees maintain its commitment? For Kristen, there was a clear connection between Coastal Coffee's involvement in fair trade and her family's experience of interacting directly with farming communities. As noted above, their initial interest in fair trade came as a result of a family trip to Central America. Later, her mother made a second trip, the effect of which Kristen described to me:

That was the first experience for my mom of really getting out of the United States to someplace other than Europe and seeing people that live in extreme poverty - and realizing that the coffee that she sells everyday is grown by these people. That was life changing for her. And by the end of the year, we were all down there... And she just felt like she, you know, she had to get my dad and myself on board with this because it was a mission for her.

In reflecting on her own experience visiting with coffee farmers, Kristen explained that moving Coastal Coffees in the direction of fair trade was not a tough sell because it involved what she described as a "personal transformation". "I became a different person," she said, after meeting with farmers. "It [was] hard to actually witness the suffering of other human beings and not feel some responsibility to be involved in improving the situation." Statements such as these suggest that Coastal Coffee's involvement in fair trade coffee should be understood as much through a social and moral lens as through a narrow economic one. Viewing its decisions as driven primarily by business considerations does not do justice to the complexity of the situation, let alone Kristen's first-hand account. The influences were multifaceted and point in many ways to other-oriented motivations that directed the company. 
In terms of Figure 8.1, Coastal Coffees was willing and able to make decisions that placed them in quadrant I, where it could increase the likelihood of social returns even though economic benefits were less clear. It was willing, at times, to act contrary to market pressures because of the direct experiences members of the company had had with the people who were impacted by their business decisions. Importantly, the effect of these direct encounters were more than cerebral and emotional. Indeed, they led the company to alter its actual business practices. These observations point to the impact that such encounters can have.

\section{Discussion and conclusion}

The case of Coastal Coffees serves two purposes. First, it illustrates how social enterprise can be a complicated endeavor despite slogans and advertising campaigns to the contrary. Decisions that, at a distance, might appear to have win-win outcomes necessarily involve tradeoffs when inspected closely. Second, the case of Coastal Coffees illustrates one reason why a forprofit social enterprise might be willing to act against its financial interests. Calling again upon Figure 8.1, the case provides a clue as to why such businesses do not operate only in quadrants II and IV, although this is where much of conventional wisdom would place them.

During the course of my fieldwork, it became clear that social enterprises were willing and able to act against market pressures for a variety of reasons. I have not considered all of these reasons here but have focused on one that was particular to the fair trade industry and that raises interesting questions about the accomplishment of social enterprise - at least how they might be expected to pay due attention to their financial goals as well as their prosocial ones. In using the case of Coastal Coffees, I have aimed to add flesh to the idea that meaningful encounters with others who are impacted by a business's decisions can cause members of that business to alter conventional market-oriented activity. Other men and women I studied shared experiences similar to the Harpers', although space limitations do not allow me to record them here.

The specific kinds of encounters highlighted here are those that bring together individuals who are part of the same social and economic network - for example, actors at opposite ends of the supply chain - in ways that, under conventional business practice, would not typically take place. Relationships like these are especially likely to develop in the fair trade industry, where direct interactions are encouraged: traders interact with producing communities from developing nations for economic reasons - to exchange money for goods, to settle on contracts, to monitor production facilities and processes, for training purposes, and so on. Such encounters are notable because they put businessmen and women into direct contact with the very people who are impacted by their decisions. As images of 
poverty or need weighed upon business practitioners, or as business associations evolved into meaningful friendships, it became difficult for some of the US-based importers whom I interviewed to think of interacting with farmers and artisans in a business-as-usual manner. Such encounters created a kind of blockade against market pressures.

Of course, not all interactions with others motivate prosocial outcomes, so it is important to qualify what we can and cannot say based on these evidences. To conclude that placing members of a financial network into direct contact with each other will alter the way they do business with each other is too simple a recipe. Other factors are at play, and scholars of social enterprise would do well to study them. My own research, for example, suggests that many people come to their work in social enterprise primed to be motivated by meaningful encounters with others. That is, there is a certain selection effect at work. Yet selection is not the only mechanism operable, as the case of Coastal Coffees illustrates. The Harpers were in the coffee business for decades before they developed an interest in fair trade. Their encounters with farmers impacted on them in such a way as to motivate moving the business in a more prosocial direction, even when the financial returns were not clear. Encounters like those that they experienced, therefore, can have a kind of treatment effect that works independently of selection effects.

There are other conditions as well that likely play a part in creating the outcomes illustrated in the case of Coastal Coffees. For example US-based traders perceived their efforts as noble, thus allowing them to enact their own caring self-images. They also had a sense of efficacy in that they believed that their other-oriented actions could and would make a meaningful difference. Because the size of fair trade organizations tend to be small, the practitioners I studied also had significant freedom to shape the direction of the companies that they led. All of these considerations, and no doubt others (such as the industry setting), could be further examined in order to understand the workings of and pressures on social enterprises.

In summary, research on the fair trade industry, including this case study of Coastal Coffees, highlights the complicated and sometimes contradictory nature of these ventures. The point in suggesting that it is a flawed or paradoxical proposition is not to argue that social enterprise has no place in the organizational landscape but rather to open the door wider for thoughtful scholarship. With important exceptions, what writing has been done on social enterprise tends to be anecdotal, sympathetic and boosterish. By starting from the premise that win-win outcomes are plentiful, we close the door to the range of possible outcomes, some of which may be less than optimal. Considering the problematic nature of social enterprise may be discomfiting for practitioners and academics who are hopeful about its possibilities, yet such scholarship allows not only dialogue about the unique challenges to social enterprises but how they might constructively be addressed. 
Are there lessons here for practitioners and scholars? Certainly. For practitioners (and their stakeholders) who are concerned about mission drift in the face of considerable financial pressures, the argument suggests that putting employees into direct contact with the consequences of their efforts can provide incentives to keep them committed to the organization's prosocial goals. One particularly successful fair trade company that I studied, for example, regularly sends all new employees to producing communities. Doing so, a board member explained to me, helps employees - even accountants and marketing agents, whose work would otherwise be removed from the farmers' lives - to recognize the larger value of what they are doing. Yet putting employees in contact with the consequences of their work will certainly not work in every situation, and this is where scholars could make a useful contribution. More work could be done to understand the conditions under which the outcomes described in the case of Coastal Coffees (and other organizations) obtain. This could fruitfully involve close analysis of a case in which face-to-face encounters occur but a prosocial outcome does not result.

It is because win-win situations are in short supply and lose-lose situations are unambiguously avoided that, theoretically speaking, social enterprise can be considered a fundamentally problematic proposition. Realistically, social entrepreneurs are left to decide where and how their decisions should be distributed across quadrants I and IV, both of which introduce unique challenges to the potential longevity of the venture. This is the difficult material and normative environment in which social enterprises must operate. The conceptual schema in Figure 8.1 and the case of Coastal Coffees ultimately shed light on how social enterprises navigate this terrain and balance their commitments. I have problematized social enterprises conceptually, provided a way to think about their competing goals and offered one perspective on how such ventures might negotiate their differential demands.

\section{References}

Bornstein, David. 2004. How to Change the World: Social Entrepreneurship and the Power of New Ideas. New York: Oxford University Press.

Child, Curtis. 2011. "Social Enterprise and the Problem of Competing Logics: Profits and Prosocial Missions in the Fair Trade and Socially Responsible Investing Industries."

Cooney, Kate. 2006. "The Institutional and Technical Structuring of Nonprofit Ventures: Case Study of a U.S. Hybrid Organization Caught Between Two Fields." Voluntas 17: 143-161.

Cooney, Kate and Trina R. Williams Shanks. 2010. "New Approaches to Old Problems: Market-Based Strategies for Poverty Alleviation." Social Service Review 84: 29-55.

Edwards, Michael. 2008. Just Another Emporer? The Myths and Realities of Philanthrocapitalism. Demos: A Network for Ideas and Action; The Young Foundation. 
Fair Trade USA. 2010. 2010 Almanac, www.transfairusa.org/resource-library /downloads

Fridell, Gavin. 2007. Fair Trade Coffee: The Prospects and Pitfalls of Market-driven Social Justice. Toronto: University of Toronto Press.

Krier,Jean-Marle. 2008. "New Facts and Figures from an Ongoing Success Story: A Report on Fair Trade in 33 Consumer Countries," The Dutch Association of Worldshops, www.wfto.com/index.php?option=com_docman\&task=doc_download\&gid= $1110 \& \&$ Itemid=109

Lynch, Kevin and Julius Walls. 2009. Mission Inc.: The Practitioners Guide to Social Enterprise. San Francisco: Berrett-Koehler Publishers.

Prahalad, C. K. 2004. The Fortune at the Bottom of the Pyramid: Eradicating Poverty Through Profits. Upper Saddle River: Wharton School Publishing.

Taylor, Celia R. 2010. "Carpe Crisis: Capitalizing on the Breakdown of Capitalism to Consider the Creation of Social Businesses." New York Law School Law Review 54: 743-771.

TransFair USA. 2010. Annual Report 2009, www.transfairusa.org/resource-library /financial-information

Yunus, Muhammad. 2008. Creating a World Without Poverty: Social Business and the Future of Capitalism. New York: PublicAffairs.

Yunus, Muhammad and Karl Weber. 2010. Building Social Business: The New Kind of Capitalism that Serves Humanity's Most Pressing Needs. New York: Public Affairs. 